\title{
ASPEK HUKUM ISLAM DALAM KEBUDAYAAN SUNDA
}

\author{
Oleh: Dr. H. Yat Rospia Brata, Drs., M.Si. ${ }^{*}$
}

\begin{abstract}
This article describes and analyzes aspects of Islamic law in Sundanese culture. Starting from the fact that the Sundanese have very strong ties with religion, especially Islam, so that the jargon appears that Sundanese is identical with Islam, it is considered anomaly if there are people who are non-Muslim Sunda let alone not adhere to religion. This paper describes that the Sundanese have a very strong ethic and culture rooted in the community long before the coming of Islam. When Islam came, the values of ethics and culture of the Sundanese turned out to have values in common with Islamic values, which is why Islam is easily accepted by the Sundanese and merged with the values of Islamic teachings so reasonable if there is a statement that states that Islam identical with Sundanese and Sundanese is identical with Islam.
\end{abstract}

Keywords: Sundanese culture, Islamic law

\begin{abstract}
Abstrak
Artikel ini mendeskripsikan dan menganalisis aspek hukum Islam dalam kebudayaan Sunda. Bertolak dari kenyataan bahwa orang Sunda memiliki ikatan yang sangat kuat dengan agama, khususnya Islam, sehingga muncul jargon bahwa Sunda identik dengan Islam, maka dianggap anomali jika ada orang Sunda yang beragama non muslim apalagi tidak menganut agama. Tulisan ini memaparkan bahwa orang Sunda memiliki etika dan budaya yang sangat kuat mengakar di masyarakat jauh sebelum datangnya Islam. Ketika Islam datang, nilai-nilai etika dan budaya orang Sunda ternyata memiliki nilai-nilai kesamaan dengan nilai-nilai Islam, itulah sebabnya Islam dengan mudah diterima oleh orang Sunda dan melebur dengan nilai-nilai ajaran Islam sehingga wajar jika ada pernyataan yang menyatakan bahwa Islam identik dengan Sunda dan Sunda identik dengan Islam.
\end{abstract}

Kata Kunci: Kebudayaan Sunda, Hukum Islam

\section{Pendahuluan}

Budaya daerah mempunyai sejarah panjang dan memiliki kearifan serta keunggulannya masing-masing. Pada dirinya, budaya itu mengandung unsurunsur yang oleh para founding fathers negara Indonesia disarikan dalam nama Pancasila. Budaya-budaya daerah yang secara sadar dikembangkan dalam suasana keterbukaan, akan dinamis dan mampu mencari pengungkapan sesuai dengan lingkungan yang berubah dan sekaligus menjadi penyumbang bagi

\footnotetext{
*) Dosen Tetap FKIP Universitas Galuh
} 
pembentukan pola (sistem) kemasyarakatan yang majemuk sehingga dapat hidup bersama.

Budaya atau kebudayaan menurut Kusdi (2011: 12) berasal dari bahasa sansekerta yaitu buddhayah, yang merupakan bentuk jamak dari buddhi (budi dan akal) yang diartikan sebagai hal-hal yang berkaitan dengan budi dan akal manusia. Hal tersebut tampaknya menekankan kepada aspek kolektif bahwa budaya adalah hasil kerja dari sejumlah akal dan bukan hanya dari satu akal individual saja. Dalam bahasa Inggris, kebudayaan berasal dari kata culture, yang berasal dari kata latin colere, yaitu mengelola dan mengerjakan. Bisa diartikan juga sebagai mengelola tanah dan atau bertani. Kata culture kadang juga diterjemahkan sebagai "kultur" dalam bahasa Indonesia.

Relevan dengan definisi di atas, Wibowo (2007: 15) menjelaskan bahwa budaya merupakan kegiatan manusia yang sistematis diturunkan dari generasi ke generasi melalui berbagai proses pembelajaran untuk menciptakan cara hidup tertentu yang paling sesuai dengan lingkungan tempat tinggalnya.

Berdasarkan berbagai definisi di atas, budaya dapat disimpulkan sebagai segala sesuatu yang ada dalam masyarakat yang menjadi sistem nilai yang dianut bersama, menjadi kebiasaan dan menjadi identitas bagi masyarakat tersebut.

Adapun dasar hukum kebudayaan tertuang dalam Pasal 32 UndangUndang Dasar 1945 Amandemen ke 4, yakni:

(1)Negara memajukan kebudayaan nasional Indonesia di tengah peradaban dunia dengan menjamin kebebasan masyarakat dalam memelihara dan mengembangkan nilai-nilai budayanya.

(2)Negara menghormati dan memelihara bahasa daerah sebagai kekayaan budaya nasional.

Para perumus perubahan UUD 1945 tersebut menyadari betul terhadap peran penting kebudayaan dalam pembentukan jati diri masyarakat dan bangsa Indonesia pada khususnya, serta bagi modernitas dan kemajuan bangsa secara umum. Pengembangan budaya Indonesia adalah tanggung jawab negara, bukan hanya pemerintah tetapi juga masyarakat. Amandemen juga menggaris-bawahi bahwa identitas Bangsa Indonesia yakni Bhinneka Tunggal Ika harus dihayati, karena persatuan (Tunggal) akan selalu ada bersama dengan kemajemukan (Bhinneka). 
Sementara itu hukum sangat berkaitan erat dengan kebudayaan, hukum sendiri (hukum positif) merupakan produk kebudayaan karena sejatinya produk hukum adalah produk ciptaan manusia. Dalam studi hukum dikenal struktur hukum, substansi hukum, dan budaya hukum. Hukum diciptakan memiliki karakteristik yang berbeda-beda dari satu daerah ke daerah lainnya sesuai dengan kebudayaan setempat. Artinya, kebudayaan membentuk hukum.

Menurut Rahardjo (2010: i) hukum itu bukanlah skema yang final tetapi terus bergerak sesuai dengan dinamika dan perkembangan zaman umat manusia. Artinya, hukum akan terus berubah sesuai dengan perkembangan zaman dan dinamika manusia ini terlahir dalam proses kebudayaan yang berbeda.

Berdasarkan pandangan ini dapat dipahami bahwa hukum itu berkaitan dengan manusia dan kebudayaan. Hukum yang lahir dari kebudayaan merupakan suatu proses hukum yang lahir dengan cara bottom-up, dari grass root (akar rumput) masyarakat, dari kaidah-kaidah kepercayaan, spiritual, dan kaidah sosial yang ada di masyarakat menjadi suatu hukum yang berlaku. Hukum Adat juga demikian, ada karena budaya di masyarakat yang membangunnya. Adapun bahwa Hukum Adat antara masyarakat Sunda, masyarakat Minang, masyarakat Bugis adalah berbeda. Ini adalah suatu konsep pluralisme hukum (legal pluralism) dimana hukum hadir dalam bentuk kemajemukan kebudayaan.

Kebudayaan Sunda termasuk salah satu kebudayaan suku bangsa di Indonesia yang berusia tua, bahkan dibandingkan dengan kebudayaan Jawa sekalipun, setidaknya dalam hal proses pengenalan terhadap budaya tuilsan. Kegemilangan kebudayaan Sunda di masa lalu, khususnya semasa Kerajaan Tarumanegara dan Kerajaan Sunda, dalam perkembangannya kemudian seringkali dijadikan acuan dalam memetakan apa yang dinamakan Kebudayaan Sunda. Kebudayaan Sunda yang ideal pun kemudian sering dikaitkan sebagai kebudayaan raja-raja Sunda di masa lalu. Dalam kaitan ini, jadilah sosok Prabu Siliwangi dijadikan sebagai tokoh panutan masyarakat Sunda karena dipandang sebagai raja Sunda yang berhasil, sekaligus mampu memberikan kesejahteraan kepada rakyatnya.

Demikian pula dengan budaya lisan dalam Kebudayaan Sunda sebenarnya merupakan budaya yang telah lama akrab dengan komuntias 
Sunda, bahkan usianya jauh lebih tua dibandingkan dengan budaya baca dan tulisan. Namun budaya ilsan dalam pengertian kapasitas untuk mengemukakan pendapat serta berjiwa besar dalam menghadapi pendapat yang berbeda masih merupakan barang yang masih sangat langka dalam Kebudayaan Sunda (Dienaputra, 2003: 13)

Tradisi lisan Sunda tampaknya baru mampu menghargai komunikasi model monolog dan bukannya dialog. Akibatnya kemampuan untuk menyampaikan pendapat dan menerima pendapat yang berbeda dalam Kebudayaan Sunda merupakan barang yang cukup mewah, padahal kapasitas untuk mengemukakan pendapat dan menerima pendapat yang berbeda ini menjadi salah satu dasar bagi munculnya daya hidufp dan mutu hidup kebudayaan yang berkualitas. Kapasitas mengemukakan pendapat pada dasarnya merupakan representasi dari kemampuan bernafas dan mencerna, sementara kapasitas menerima dengan jiwa besar pendapat yang berbeda lebih merupakan representasi dari kemampuan berkoordinasi dan berorganisasi, kemampuan beradaptasi, kemampuan mobilitas, kemampuan tumbuh dan berkembang, serta kemampuan regenerasi.

Dalam Sosiologi-Antropologi, dikenal kebudayaan sebagai sistem norma, yaitu seperangkat perilaku yang diharapkan, suatu citra kebudayaan tentang bagaimana seseorang seharusnya bersikap. Mengingat kebudayaan itu menyangkut aturan yang harus diikuti, sehingga dapat dikatakan bahwa kebudayaan bersifat normatif, yang merupakan cara lain untuk mengatakan bahwa kebudayaan menentukan standar perilaku. Misalnya, untuk bersalaman mengulurkan tangan kanan. Ini adalah pantas dalam kebudayaan Sunda. Untuk menggaruk kepala boleh menggunakan kedua belah tangan karena kebudayaan Sunda tidak memiliki norma untuk menggaruk kepala, oleh sebab itu pada dasarnya bahwa kebudayaan dapat berwujud berupa; kebiasaan, tata kelakuan, lembaga, dan nilai (Horton dan Hunt, 1996: 64).

Berdasarkan hal di atas, tulisan ini berusaha menjelaskan aspek hukum Islam dalam kebudayaan Sunda.

\section{Pembahasan}

Manakala mengupas tentang kebudayaan Sunda, pada tahapan awal saja sudah banyak permasalahan yang akan muncul, sehingga sebelum 
sampai pada pembahasan tentang substansi kebudayaan Sunda, pembicaraan sudah akan menjadi hangat ketika timbul pertanyaan tentang makna Sunda dalam kebudayaan Sunda.

Sunda dalam kebudayaan Sunda apakah dipahami sebagai sebuah etnisitas atau sebagai wilayah geografis. Manakala Sunda dipahami sebagai sebuah wilayah geografis maka untuk menetapkan mana yang dimaksud wilayah atau tanah Sunda bukanlah merupakan hal yang mudah. Jawa Barat sebagai tempat bermukimnya urang Sunda tidaklah lantas dapat dikatakan sebagai wilayah Sunda. Era otonomi daerah yang kini bergerak kencang semakin memperlihatkan sulitnya wilayah Jawa Barat untuk dapat dikatakan sebagai tanah Sunda.

Untuk menetapkan sebuah wilayah geografis yang bernama wilayah Sunda bukanlah sesuatu yang mudah, malahan bila hal tersebut dilakukan dengan tidak hati-hati, bisa menimbulkan kegoncangan yang cukup serius, lantas kalau Jawa Barat sudah sulit untuk direpresentasikan sebagai tanah Sunda, masih adakah wilayah yang bisa dinamakan sebagai tanah Sunda atau daerah manakah sebenarnya yang bisa dikatakan sebagai tanah Sunda. Dalam kaitan ini, Edi S. Ekadjati (1995: 7-8) mengatakan bahwa tanah Sunda merujuk pada bekas wilayah Kerajaan Sunda Pajajaran, yang kemudian berdiri sendiri, yakni Sumedang Larang, Banten, Cirebon, dan Galuh. Sumedang Larang dan Galuh kemudian menjadi satu wilayah kesatuan dengan nama Priangan. Dalam perkembangan berikutnya, Priangan sering dikatakan sebagai pusatnya tanah Sunda.

Selanjutnya apabila Sunda dipahami sebagai sebuah etnisitas, maka permasalahannya tidak serumit mendefinisikan wilayah atau tanah Sunda. Dalam kaitan ini, urang Sunda secara sederhana dapat diartikan sebagai orang yang mengaku dirinya dan diakui oleh orang lain sebagai orang Sunda (Suwarsih, 1987: 1).

Dalam pengertian tersebut setidaknya tercakup dua kriteria besar yang dapat dijadikan pegangan untuk menyebut seseorang sebagai urang Sunda atau bukan urang Sunda. Kriteria pertama didasarkan atas keturunan atau hubungan darah. Dengan demikian, seseorang dikatakan urang Sunda apabila orang tuanya, baik dari pihak ayah maupun ibu, atau keduanya adalah orang Sunda, terlepas dimana ia berada atau dibesarkan. Kriteria kedua didasarkan 
atas kondisi sosial budaya. Seseorang dikatakan urang Sunda apabila ia dibesarkan dalam lingkungan sosial budaya Sunda dan dalam hidupnya menghayati serta mempergunakan norma-norma dan nilai-nilai budaya Sunda. Dalam kriteria kedua ini, yang diangggap penting adalah tempat tinggal, kehidupan sosial budaya, dan sikap orangnya (Edi S. Ekadjati, 1995: 8).

Permasalahan tentang urang Sunda ini barulah muncul manakala akan menetapkan kriteria yang akan digunakan untuk menentukan urang Sunda. Dalam kaitan ini, memang sering timbul perdebatan yang terpolarisasi; kutub pertama yang menggunakan kedua kriteria sebagai dasar untuk menetapkan urang Sunda, dan kutub berikutnya yang hanya menentukan salah satu kriteria sebagai dasar untuk menentukan urang Sunda. Perdebatan akan semakin meruncing ketika memasuki wilayah politik, terutama berkaitan dengan perebutan kursi kekuasaan. Bila Sunda dalam kekuasaan Sunda dipahami sebagai sebuah etnisitas semata, maka Kebudayaan Sunda adalah merupakan hasil karya, karsa, dan cipta urang Sunda.

Sementara itu mengenai aspek hukum Islam dalam kebudayaan Sunda, Mustofa (Praja, 2005: 157-169) memberikan penafsiran pada ayat awal surat alBaqarah dengan pernyataan bahwa: "Urang Sunda mah geus Islam memeh Islam (Orang Sunda sudah Islami sebelum Islam datang)". Kenyataan ini dapat dibuktikan bahwa hampir seluruh ranah kehidupan orang Sunda mengandung nilai-nilai hukum yang Islami. Ajaran dan hukum dalam masyarakat Sunda pun disosialisasikan melalui seni dan budaya, seperti lakon pewayangan (wayang golek), lagu-lagu, pantun, maupun banyolan.

Ajaran Islam melalui media wayang golek meliputi Islam sebagai way of life, termasuk ajaran dasar tentang ketatanegaraan dan pemerintahan. Ajaran Islam melalui pewayangan seringkali menekankan kepada ajaran agama dan negara secara entitas, bersamaan, dan berkesinambungan yang mencerminkan pemahaman atas perintah ketaatan kepada Allah, Rasul dan ulil amri sebagaimana disebutkan dalam Q.S. al-Nisa ayat 59. Demikian pula kreol yang dilambangkan dengan jiman layang kalimusada dalam cerita pewayangan Sunda (wayang golek) yakni dua kalimat syahadat menjadi pemicu gerak dan langkah manusia Sunda yang dapat menjadi penawar bagi penyelesaian berbagai masalah kehidupan dan juga penyakit. 
Demikian pula lagu-lagu Sunda pun sarat dengan ajaran dan hukum Islam, baik yang melembaga, seperti lagu-lagu Cigawiran, Ciawian, dan Cianjuran (Nurjamin, t.th., 157-169), maupun lagu-lagu yang biasa didendangkan oleh para santri kalong di masjid, tajug, madrasah yang meliputi ajaran tauhid, hukum, hingga ajaran tentang hidup berkeluarga, seperti pada lagu-lagu sawer panganten. Ajaran monotheism (tauhid) seringkali didendangkan melalui sifat dua puluh yang terumuskan oleh al-lji dan dikaji di pesantren dan masjid-masjid dalam kitab Tijan dan Qathr al-Ghayats.

Ajaran Islam sebagai agama pun telah melembaga dalam upacara adat, khususnya perkawinan. Pesta perkawinan ternyata mengadopsi istilah walimah dalam teks hadist yang menyerukan upacara atau pesta perkawinan. Sementara kedudukan wanita sebagai ibu rumah tangga dan pria sebagai pencari nafkah digambarkan dalam pamajikan yang menurut sastra Sunda berasal dari bahasa Arab "Famaaji uka" (tempat kembali setelah mencari nafkah).

Ajaran ilmu waris (mawaris) dalam Islam direpresentasikan dalam kalimat sageugeus saeundan atau sakalek satanggungan, yang memiliki konotasi bahwa laki-laki itu memiliki bagian 2 (dua), adapun perempuan adalah 1 (satu) atau bagian wanita sesuai kapasitas dan kodratinya yang setengah kemampuan memikul barang yang dapat dilakukan seorang laki-laki (Praja, 2005: 135). Sementara itu rujukan ajaran Islam pun diajarkan sesuai dengan perkembangan zaman, antara lain dalam bentuk cetakan, baik tafsir bahasa Sunda, hadist, maupun hukum Islam atau fiqh. Hukum Islam ada yang dicetak dalam bahasa Sunda dengan menggunakan huruf Arab dan dewasa ini dicetak dalam huruf latin, seperti Tafsir al-Bayan dan Tafsir Rahmat (Safei, 2005: 141-145). Selain itu, banyak kata dalam bangsa Arab diserap ke dalam bahasa Sunda sebagai sebuah toponimik, seperti jisim abdi untuk menyebut diri sendiri yang sepenuhnya diambil dari bahasa Arab yaitu jisim (badan) dan abdi (hamba), yakni hamba dalam pengertian Allah (Praja, 2005: 137).

Penjelasan di atas, menunjukkan bahwa Islam dalam tata kehidupan orang Sunda begitu selaras dengan adat. Terlebih jika dilihat pada kenyataan bahwa sejak zaman kerajaan Sunda dan Galuh, suasana keberagamaan masyarakat Sunda telah menciptakan kehidupan harmonis dalam semua bidang kehidupan. Terdapat beberapa hal menarik yang patut diapreasiasi tentang keberagamaan masyarakat Sunda sebelum masuknya Islam ke tatar Sunda. 
Pertama, adanya kebebasan dalam beragama, sehingga orang bebas memilih agama dan sekte menurut keyakinan masing-masing-masing. Kedua, terjadinya sinkretisme dalam ajaran agama dan kepercayaan, misalkan animisme, hinduisme, budhisme, dan Islam. Semua agama tersebut mengalami sinkretisme dalam perjalanan hidup manusia. Ketiga, kedua hal tersebut berlangsung secara damai dan alamiah sehingga tidak pernah terjadi konflik antara penganut agama yang satu dengan yang lainnya (Ekadjati, 2005: 172).

Menurut Ekadjati (2005: 175) kajian atas sumber-sumber informasi mengenai keagamaan pada zaman Sunda masa lampau menunjukkan bahwa masyarakat Sunda telah memiliki gambaran tentang beberapa konsep esensial. Pertama, gambaran tentang ketuhanan menurut persepsi orang Sunda sendiri. Kedua, gambaran tentang kehidupan sesudah kematian. Ketiga, gambaran tentang cara-cara untuk mendapatkan keselamatan di dunia dan di akhirat dengan melakukan amal dan tapa sesuai dengan kedudukannya.

Selain itu juga, Residen Priangan Oosthout menegaskan bahwa orang Sunda lebih bersemangat dan teguh dalam beragama ketimbang orang Jawa. Misalnya, menurut Kern, pada tahun 1925 di wilayah Keresidenan Priangan, tidak ada kabupaten yang demikian kuat dan tinggi perhatiannya dalam mempelajari pengetahuan agama, serta berkembang dengan baik seperti Cianjur. Bahkan perkataan kafir, musyrik atau syirik pada waktu itu, sangat menyinggung harga diri orang yang mengaku Islam meskipun dalam tataran praktis banyak menjalankan ajaran-ajaran sinkretis (Iskandar, 2001: 55-57).

Dalam proses penyebaran agama Islam di tatar Sunda, tidak seluruh wilayah tanah Sunda menerima sepenuhnya. Di beberapa tempat meski dalam lingkup kecil, terdapat komunitas ekslusif yang masih mempertahankan ajaran leluhurnya seperti halnya komunitas masyarakat Kampung Naga Tasikmalaya, Kelompok Madrais Cipari Kuningan, dan komunitas yang mendiami Desa Kanekes, Kecamatan Leuwidamar, Kabupaten Lebak yang dikenal dengan masyarakat Baduy. Mereka adalah komunitas yang tidak mau memeluk agama Islam dan terkungkung di satu wilayah religious yang khas, terpisah dari Muslim Sunda dan tetap melanggengkan ajaran Sunda Wiwitan.

Meskipun demikian, ada juga orang Baduy yang memeluk agama Islam, berdasarkan hasil penelitan Ali Khomsan dan Winati Wigna (2009: 64-65) bahwa Baduy Muslim jauh lebih banyak yang mempunyai kemampuan baca dan tulis 
dibanding dengan Baduy Luar. Sejumlah 92\% suami atau istri mempunyai kemampuan baca dan tulis. Hal ini menunjukkan bahwa memang Baduy Muslim jauh lebih terbuka dan lebih maju dibandingkan dengan Baduy Luar dan juga Baduy Dalam. Orang Baduy baik Baduy Luar maupun Baduy Dalam dilarang sekolah oleh adat. Bagi orang Baduy, orang pintar tidak dibutuhkan, yang penting adalah orang yang ngarti (mengerti) sehingga tidak ditipu dan dibodohi oleh orang lain.

Sebagaimana pendapat Gungun Senoaji (2010: 305) bahwa ajaran etika atau akhlak di kalangan Baduy prinsipnya sejalan dengan ajaran Islam. Hal itu tergambar dari pokok-pokok ajaran hidupnya yang dikenal dengan "pikukuh Baduy". Hal ini sejalan dengan pendapat Retty Isnende (2016: 204) bahwa pada masyarakat Baduy, pikukuh karuhun diterapkan secara baku dalam kehidupan sehari-hari mereka sebagai adat yang ditetapkan secara resmi dan tersusun serta tersistem pada penanggalan adat Baduy dari mulai bulan Safar (Kapat) awal tahun sampai bulan ketiga akhir tahun.

Sensus penduduk tahun 2016, Islam di Jawa Barat dipeluk oleh 45.958.007 orang yang merupakan $97 \%$ jumlah penduduk Jawa Barat. Tercatat pula 172.521 buah masjid, 4.772 buah pesantren, 150.927 orang kyai, 34.494 orang ulama, dan 36.201 orang mubaligh yang tersebar merata di seluruh pelosok Jawa Barat. Dengan keadaan tersebut, dapat dikatakan bahwa rakyat Jawa Barat (Sunda) hampir seluruhnya beragama Islam dengan kata lain bahwa orang Jawa Barat (Sunda) adalah bergama Islam (https://ms.wikipedia.org/wiki/Jawa_Barat).

Dari sisi ekonomi umat, bisa dilihat bahwa fenomena tumbuhnya lembagalembaga perekonomian kerakyatan bernuansa keagamaan, sampai akhir 2006 di Jawa Barat telah berdiri tidak kurang dari 300 Baitul Mal Wattamwil (BMT) yang langsung dibina oleh Pusat Inkubasi Bina Usaha Kecil (PINBUK) ditambah dengan 348 Koperasi Pondok Pesantren (Kopontren) yang dibina oleh Puskopontren Jawa Barat (Safei, 2005: 146).

Fenomena tersebut merupakan penggambaran nilai-nilai Islam dalam kehidupan masyarakat Sunda serta data statistik tentang kekuatan pendidikan dan ekonomi umat, maka dapat dinyatakan secara tegas bahwa Islam khususnya dalam bidang hukum di tatar Sunda memiliki potensi yang tidak dimilki oleh masyarakat Islam di daerah lain, sehingga sepatutnya masyarakat 
Islam Sunda merasa bangga akan hal tersebut dan berusaha menunjukkan kepada dunia bahwa Islam Sunda adalah sebuah entitas.

\section{Kesimpulan}

Dialog antara Islam dan Budaya lokal sebagai bukti bahwa antara agama (Islam) dan kebudayaan merupakan dua hal yang tidak bisa dipisahkan, keduanya saling melengkapi satu sama lain. Ketika berbicara agama dan kebudayaan, bisa dilihat melalui aplikasi fungsinya dalam wujud sistem budaya dan juga dalam bentuk tradisi ritual atau upacara keagamaan yang nyata-nyata bisa mengandung nilai agama dan kebudayaan secara bersamaan. Pertemuan antara ajaran leluhur Sunda dan ajaran Islam melahirkan pandangan pendidikan yang khas dan mudah diterima di kalangan masyarakat Sunda. Begitu pula dalam persoalan hukum Islam bahwa hal-hal yang menyangkut syari'ah yang berhubungan dengan mu'amalah (sosial) senantiasa sejalan dengan adat istiadat yang hadir pada kebudayaan Sunda.

\section{Daftar Pustaka}

Dienaputra, Reiza, 2003, Kebudayaan Sunda: Antara Mitos Dan Realitas, Makalah dalam Seminar Nasional, dengan tema, "Menggugat Budaya Sunda: Perspektif Periferal", yang diselenggarakn oleh Perhimpunan Mahasiswa Bogor Daerah Istimewa Yogyakarta (PAMOR RAYA), bertempat di Balai Utari Mandala Bhakti Wanitatama, Yogyakarta.

Ekadjati, Edi S, 1995, Kebudayaan Sunda (Suatu Pendekatan Sejarah, Jakarta, Pustaka Jaya.

2005, Kebudayaan Sunda: Zaman Pajajaran, Jilid II, Jakarta, PT Dunia Pustaka Jaya.

Horton, Paul B. dan Chester L Hunt, 1996, Sosiologi Jilid 1, Jakarta, Erlangga, 1996.

Iskandar, Muhammad, 2001, Para Pengemban Amanah: Pergulatan Pemikiran Kiai dan Ulama di Jawa Barat 1900-1950, Yogyakarta: Mata Bangsa.

Isnendes, Retty, 2016, Upacara Seba Baduy: Sebuah Perjalanan Politik Masyarakat Adat Sunda Wiwitan, dalam Jurnal Masyrakat \& Budaya, Volume 18 No. 2 Tahun 2016.

Kahmad, Dadang, 2005, Agama Islam dalam Perkembangan Budaya Sunda: dalam Cik Hasan Bisri dkk (penyunting). Pergumulan Islam dengan Kebudayaan Lokal di Tatar Sunda, Bandung, Kaki Langit. 
Khomsan, Ali. \& Wigna, Winati, 2009, Sosio Budaya Pangan Suku Baduy, dalam Jurnal Gizi dan Pangan, Juli 2009.

Kusdi, 2011, Budaya Organisasi, Jakarta, Salemba Empat.

Nurjamin, Asep, 2005, Cigawiran: Tembang Sunda dari Pesantren, dalam Cik Hasan Bisri dkk (penyunting). Pergumulan Islam dengan Kebudayaan Lokal di Tatar Sunda, Bandung, Kaki Langit.

Praja, Juhaya S, 2005, Hukum Islam dalam Tradisi dan Budaya Masyarakat Sunda, dalam Cik Hasan Bisri dkk (penyunting). Pergumulan Islam dengan Kebudyaan Lokal di Tatar Sunda, Bandung, Kaki Langit.

Rahardjo,Satjipto, 2010, Penegakan Hukum Progresif, Jakarta, Kompas.

Safei, Agus Ahmad, 2005, Fenomena Kultural Islam Sunda, dalam Cik Hasan Bisri dkk (penyunting). Pergumulan Islam dengan Kebudayaan Lokal di Tatar Sunda, Bandung, Kaki Langit.

Senoaji, Gungun, 2010, Dinamika Sosial dan Budaya Masyarakat Baduy dalam Menegelola hutan dan Lingkungan, dalam Jurnal Bumi Lestari Vol. 10 Nomor 2 Agustus 2010

Warnaen, Suwarsih, 1987. Pandangan Hidup Orang Sunda. Bandung, Bagian Proyek Penelitian dan Pengkajian Kebudayaan Sunda (Sundanologi) Depdikbud.

Wibowo, 2007, Manajemen Kinerja. Jakarta, Rajawali Pers

\section{Perundang-Undangan}

Undang-Undang Dasar 1945 Amandemen ke 4

\section{Referensi Lain}

https://ms.wikipedia.org/wiki/Jawa_Barat 